\title{
EA-MDA MODEL TO RESOLVE IS Characteristic Problems in Educational INSTITUTIONS
}

\author{
Mardiana $^{1}$ and Keijiro Araki ${ }^{2}$ \\ ${ }^{1,2}$ Dept. of Advanced Information Technology, Kyushu University, Fukuoka, Japan \\ ${ }^{1}$ Dept. of Electrical Engineering, University of Lampung, Indonesia \\ mardianal ale.csce.kyushu-u.ac.jp \\ araki@csce.kyushu-u.ac.jp
}

\begin{abstract}
Higher education institutions require a proper standard and model that can be implemented to enhance alignment between business strategy and existing information technologies. Developing the required model is a complex task. A combination of the EA, MDA and SOA concepts can be one of the solutions to overcome the complexity of building a specific information technology architecture for higher education institutions. EA allows for a comprehensive understanding of the institution's main business process while defining the information system that will assist in optimizing the business process. EA essentially focuses on strategy and integration. MDA relies on models as its main element and places focuses on efficiency and quality. SOA on the other hand uses services as its principal element and focuses on flexibility and reuse. This paper seeks to formulate an information technology architecture that can provide clear guidelines on inputs and outputs for EA development activities within a given higher education institution. This proposed model specifically emphasises on WIS development in order to ensure that WIS in higher education institutions has a coherent planning, implementation and control process in place consistent with the enterprise's business strategy. The model will then be applied to support WIS development and implementation at University of Lampung (Unila) as the case study.
\end{abstract}

\section{KEYWORDS}

Enterprise Architecture, Web Information system, Higher Education, MDA, SOA

\section{INTRODUCTION}

Educational institutions play a pivotal role in society, primarily in developing countries. Educational institutions which in this case refer to higher education institutions (HEI) have business domains unlike that of business entities or other organizations. HEI or university places more emphasis on the role of information technology (IT) in supporting its business processes. Given its scale and complexity, IT management in HEI can be categorized as enterprise-scale data management. As such, particular planning and design is necessary to ensure that IT is applied in accordance with the institution's strategic objective and plan, and that it can be optimally utilized by users. The purpose of HEI in Indonesia adheres to the Triple Principles of Higher Education Institutions (Tridharma Perguruan Tinggi) that comprise education, research and community service. To ensure adherence to these principles, every university has developed their own strategic plan according to their vision and mission statements. University must also synchronize their business and technology strategies. All of these can be attained by applying the enterprise 
architecture (EA) approach within the institution. Through the optimal performance of business processes, EA can facilitate strategic planning, align business and IT resources, and regulate the lifecycle of an information system (IS) development process [1].

IS development is an aspect that should be part of an institution in order to support business activities and provide services to stakeholders, mainly in relation to data, information, technology and application. IS development should be well planned, centralized or distributed in related working units, and integrated into other existing systems. IS has helped automate many phases in the business process previously done manually in an educational institution. In line with shifts in user needs, changes to the business process are unavoidable. If an information system fails to accommodate these changing trends, its utilization will therefore be less than optimal. Hence, such changes need to be taken into account when developing an IS.

Service-oriented Architecture (SOA) helps accommodate changing business needs by providing flexibility for more efficient and effective use of IT resources. Through SOA, substantial and complex business processes are broken down into smaller and simpler services that allow for easier and faster changes to business processes [2]. SOA is equally useful for dealing with issues related to the integration of various existing systems, maintenance and improving application and systems performance. SOA however requires platform-independent services, including services that can translate all business service needs into different implementations of information technology. Model-Driven Architecture (MDA) is capable of addressing SOA weaknesses. MDA helps create an model that IS developers can make use of, which ranges from goals and requirements specification to implementation through several abstraction levels [3].

Applying the EA, MDA and SOA models together is the key element for optimizing the business processes of an enterprise. EA provides a comprehensive understanding of the core business process of an educational institution and defines the IS that contributes to the optimizing of the business process. EA essentially focuses on strategy and integration. MDA makes use of models as its main element while focusing on efficiency and quality. SOA on the other hand, depends on service as its key element while concentrating on flexibility and reuse.

The purpose of this study is to formulate an information technology architecture model that provides clearly defined directions with regard to inputs and outputs for EA development activities. EA captures a HEI as-is and to-be capabilities using a number of models and required to develop the models further. The MDA drives the models that provided from the previous activities. This proposed model specifically emphasizes on IS development by applying MDASOA to ensure that IS help align the direction of the planning, implementation and control process to remain consistent with the enterprise business strategy. The critical task of this development process are selecting the appropriate model for each phase of EA at the right level of MDA in detail. The information system will therefore meets the quality assurance (QA) standard in order to improve the educational quality of HEI in Indonesia [4]. This model will then be tested through a case study by applying the model for University of Lampung (Unila), a public university in Indonesia.

The rest of the paper is organized as follows: section 2 presents the related work. Section 3 gives key technologies and concepts. Section 4 presents analysis of WIS development in educational institution. Architectures used for creating the foundation for WIS development are described in section 5. Section 6 presents WIS development as a case study in Unila including WIS implementation and evaluation, while concluding remarks and future work are provided in section 7. 
International Journal of Software Engineering \& Applications (IJSEA), Vol.4, No.3, May 2013

\section{RELATED WORK}

Integration between business and IT is a major challenge that industries, including higher education institution must deal with. The adoption of the EA concept in this case becomes an absolute need [5]. Various models in different abstraction levels required by EA can be supported by MDA [6]. The author in [7] has described that the MDA approach can support modeling at hierarchical systems employed for aligning business and IT within an organization. The research also featured techniques applied to design hierarchical systems and developed an integrated enterprise model. A number of studies have adopted the MDA and EA frameworks to tackle modeling issues, such as [8] that described the conceptual mapping between the MDA and Zachman framework.

For web information system (WIS) development, several studies have adopted MDA such in [9] that presented the MIDAS framework. These studies focused on the structural dimension of WIS. Still adopting this framework, authors [10] have complemented the issue on navigation model construction from a user service-oriented perspective. In addition to the functional and navigational requirements of WIS, research that discussed on architectural features resulting in web specifications includes [11]. The authors have described WebSA (Web Software Architecture) based on the standard MDA. WebSA provides a set of architectural models and transformation models to specify a web application. A combination of the MDA and SOA approaches for IS is adopted in [12]. The authors have described Service-Oriented Development Method (SOD-M) that consists of models and the rules for mapping from the business view to the information view. SOD-M distinguishes between business modeling and IS in which the IS will be developed. Business view focuses on the requirement of the business, while IS focuses on the functionalities and processes.

Nevertheless, the simultaneous adoption of the EA, MDA and SOA concepts for producing an information technology architecture model for HEI is remain few. This study shall use the approach to generate an information technology architecture model and also specifically emphasize on WIS development especially for HEI to ensure that WIS has a coherent planning, implementation and control mechanism in place consistent with the business strategy of the educational institution.

\section{KeY TeChNOLOGIES AND CONCEPTS}

\subsection{Web Information System Development}

The rapid pace of IT development has led to an increasing number of information systems being transformed into web information systems (WIS) [13]. WIS is an effective platform for collecting, storing, managing and disseminating information similar to the function of traditional information systems. The difference however is that WIS can handle vast amounts of information from diverse sources undergoing fast-paced technological advancements, in different formats with high levels of complexity. This web-based system can be integrated into other WIS or nonWIS for enterprise purposes such as integration with database. Recently WIS has become a complex enterprise application. WIS normally integrates existing systems by using interactive interfaces, handles a large number of users with different access rights, and accessible through various of devices. From its development aspect, web-based systems are now more than simply about visual and user interface design. A systems developer must be familiar with the environment and current needs, and armed with the latest approaches that allow users to adapt quickly to the system. As such, WIS development is a complex task that requires approaches and effective tools to assist the developer. 
International Journal of Software Engineering \& Applications (IJSEA), Vol.4, No.3, May 2013

\subsection{IS : The Case of Higher Education Institution Indonesia}

Each HEI has its own set of strategies built on the stated vision and mission. IS must therefore be well planned to complement this strategic direction. IS that is intended in this paper refers to webbased information system or non web-based. Pursuant to government regulations in Indonesia the IS established by university must be prepared to support academic program management and quality improvement. The IS must help HEI meet its QA standard, that should at least consists of data collection, analysis, storage and retrieval, data and information presentation, and communication with relevant parties [4]. The IS evaluation standard in HEI is regulated by the government and covers several key elements, including the availability of the following components [14]:

a. Blue print on IS development, management and utilization, including systems that regulate data flow, data access authorization and disaster recovery systems.

b. Decision support systems to support top management for better planning and self-assessment analysis and more objective decision-making.

c. Database that at least should consists of information on finances, assets, facilities and infrastructure, academic administration, student and alumni profile, and teaching staff and supporting personnel.

d. IS intended for campus internal and external communication, and access to sources of academic information for students and teaching staff.

e. Internet capacity with adequate bandwidth ratio per student.

From the aforementioned elements, information systems that supports HEI activities at a minimum should encompass academic, human resource, financial and asset information systems that ideally web-based platform. An integrated WIS is crucial for the academic community to ensure easy access to data and information for learning, administrative and reporting purposes.

Management also requires an integrated WIS to support the decision-making process and for monitoring and evaluating HEI performance. Given the purpose of a HEI, and its WIS requirements along with the business process involved, it can be concluded that the data and information characteristics of a HEI are as follows: (1) distributed in every working unit and typically have different structures and standards (2) accessed by all members of the academic community with different needs, roles and level of knowledge (3) data is obtained from historical and operational data of the higher education institution (4) continued rapid data growth (5) immense data volume as academic data must be stored for a lengthy period (6) data must be periodically transferred to a different system as it has become input for another system (7) data transactions with varying time periods depending on academic calendar, peak time for certain periods such as the new academic year (8) for data reporting purposes to the central government, academic data must be based on data structure and relations set forth in the National Higher Education Database (PDPT) Data Glossary (determined by the Directorate General for Higher Education, DGHE) [15].

\subsection{Conceptualization of Information Technology Architecture Model}

Compatibility between IS application and institutional needs can be assured by taking into account the integration factor when developing the system. The essential purpose of integration is to narrow gaps found in the systems development process. Enterprise architecture helps reduce these gaps by providing model-based IS planning, designing and managing within the enterprise. With regard to HEI, the EA concept is highly relevant to be applied for maximizing the benefits of having an IS in the educational institution. The IS can therefore strategically increase HEI comparative advantage. EA in general has the following domains: Business Architecture, Information System Architecture, Technology Architecture. Business Architecture defines the 
business strategy, management, organization and business process. Information System Architecture comprises Data Architecture that describes data structure, data management and resources; and Application Architecture that defines applications required for managing data and supporting business functions. Technology Architecture represents software application infrastructure to support application development. EA has various frameworks and those that are often applied include Zachman Enterprise Architecture Framework [16] and The Open Group Architecture Framework (TOGAF) [17]. These frameworks essentially serve the same purpose of facilitating the design of the IT architecture of an enterprise. Nevertheless, preference over a particular framework also needs to be consistent with enterprise needs [18].

A key factor of EA is the compatibility between business and technology available for all stakeholders. This can be attained when all involved parties share a common perception. In this regard, modeling becomes a crucial aspect that needs to be taken into account [19]. Several models being applied however are still difficult to understand and have backgrounds that are not commonly used. Under such circumstances, the advantages of the preferred framework may not be optimally realized. A model refers to systems specification and normally presented through illustrations and texts. The ability to develop and transform models at different levels is a critical feature of MDA. The MDA is developed by The Object Management Group (OMG) [3]. The main phases of MDA process are analysis, design and model-driven implementation. This corresponds to the Computation Independent Models (CIM), the Platform Independent Models (PIM) and the Platform Specific Models (PSM). The TOGAF Architecture Development Method [ADM] [20] and MDA are mutually complementary and present immense business potential if effectively applied in combination. Hence, synergies between TOGAF and MDA will lead to improvements for the organization particularly for developing better architecture quality. From 9 phases of TOGAF ADM and requirement managements phase, the 6 specific phases have applicable and useful criteria to map to MDA. The applicable criteria are phase A (Architecture Vision) to CIM and PIM levels of MDA, phase B (Business Architecture) to CIM and PIM levels, phase C (Information System Architectures) to PIM level, phase D (Technology Architecture) to PSM level. The useful criteria are phase E (Opportunities and Solutions) and phase G (Implementation Governance) to PSM level. The proposed model in this study based on this approaches [21].

The solution to apply MDA in sync with other frameworks in order to establish the required model is expected to address any existing modeling issues. The model-driven method is a systems development approach in which the model is described in a way that clearly defines system comprehension, design, development, application, maintenance and modification. MDA in this case is intended to develop an information system that can be applied to describe enterprise business and resources. Through this form, the enterprise will gain the ability to generate specific applications and if required, make the necessary modifications according to changing needs which will later be represented in code form. Similarly, using SOA will complement the WIS being developed. Web services, as the applied technology, on the other hand shall regulate on how the system will interact and be utilized by WIS or other applications. To effectively implement SOA, it is therefore crucial to ensure an accurate analysis of the required data, ongoing business process, as well as applications and interfaces employed in running the business process in every unit within HEI. The simultaneous use of all of these approaches shall lead to a welldefined information technology architecture understandable to all stakeholders, while MDA-SOA helps ensure a more effective and manageable systems development process. 
International Journal of Software Engineering \& Applications (IJSEA), Vol.4, No.3, May 2013

\section{ANALYSIS OF WIS DEVELOPMENT IN EDUCATIONAL INSTITUTION}

In the academic world, information serves as one of the most valuable resources that need to be well managed in order to accomplish goals set by the educational institution. Education-related information as vital resource for the educational institution includes content and curriculum, learning process, facilities and infrastructure, and human resource. This indispensable resource should ideally complement and support the existing business process. In reality however, HEI in Indonesia needs to anticipate and deal with several of the following persistent issues in information systems such as redundancy, lack of standardization, lack of consolidation and inconsistency. Therefore the development strategies, requirements, issues and challenges needs to be analysed to determine the needs of educational institution.

\subsection{WIS Development Strategy}

Given the importance of WIS development, HEI as an implementing enterprise must draw up clearly defined guidelines and plans for developing a comprehensive WIS within its organization. Based on an analysis of the overall situation of the institution along with its general information system characteristics, the approach required to establish WIS within HEI must have the following qualities (1) able to integrate various existing standards and platforms (2) can be easily adapted to changes (3) facilitates the developer in the WIS development process (4) can be easily implemented (5) must have clear guidelines for evaluating WIS implementation.

Many existing information systems have been established in the HEI but are not integrated with the exist of the systems. The strategy to retain existing IS still in operation, re-engineer or replace with new systems can be seen from the system modularity parameter, on whether the existing IS can or cannot be integrated into other IS. If the existing IS is difficult to integrate, this means that it may no longer be viable to maintain the system due to its obsolete technology. Meanwhile, for existing IS that is to be maintained, the appropriate interface needs to be established to facilitate integration with other IS, or interface for the data warehouse. A new WIS is being developed in stages according to the integration standard after which the previous IS can then be terminated.

\subsection{Requirements Analysis of WIS}

Requirements analysis is intended to collect information necessary for WIS development that shall help meet HEI business goals. Requirements are identified based on the internal and external needs of the higher education institution.

\section{a. Internal Requirements}

Internal requirements are formulated according to the needs of the higher education institution as well as its departments and relevant divisions. The requirement of each department and division may differ but in general will be adjusted by conforming to the existing procedure. Given the internal requirements, the following aspects should be taken into account during IS development:

- Web-based platform

- Supports changes including with regard to changes in the curriculum, courses, codification or transcript

- Allows automation of academic transactions

- Allows the customization of functions specific to the needs of departments and working units 
International Journal of Software Engineering \& Applications (IJSEA), Vol.4, No.3, May 2013

\section{b. External Requirements}

External requirements are formulated based on government regulations applicable in Indonesia which in this case refers to the Ministry of Education, higher education policies and strategies, reporting requirements and other general requirements. Given these external requirements, the WIS to be developed must:

- Be compatible with the National Higher Education Database (PDPT)

- Support standards and formats for academic program reporting purposes to the government (DGHE) such as the EPSPED report (study program evaluation based on self-assessment) [22]

- Comply with QA standards for the accreditation of HEI issued by the National Accreditation Board for Higher Education (BAN-PT).

\subsection{Issues and Challenges}

\subsubsection{Integration}

Higher education institution needs to be encouraged to develop an WIS integrated into a model that is built according the needs of working units within the respective institution or among university. Certain data required by departments and working units as inputs is essentially the same except for differences in its usage and reporting mechanism according to their respective business process. An integrated system shall significantly support interrelated business processes and optimize its use. For example, an effective academic system that takes into account the number of students will be capable of predicting the number of required human resource (in relation to human resource system), incoming and outgoing costs (in relation to finance system), as well as the number of required classes and rooms (in relation to assets system).

To ensure integration with existing systems, new technologies should be combined with existing technologies with the least possible effort without having to redevelop ongoing systems. Based on the current situation of the existing IS in university, integration may come in the following forms:

- Data integration of different business processes, different IS functions and processes yet related to the overall work cycle, and database integration.

- Availability of an interface that can form linkages among existing IS.

- Users need not login for every WIS in order to access the required data and information. They only need to login once to enable access to all relevant WIS.

- Data that serves as output for a certain process in an IS can be the input for another IS.

\subsubsection{Interoperability}

WIS development must consider the interoperability of systems. Interoperability refers to the ability of a system to work in sync with another system that allows information exchange and the ability to use the shared information. With regard to WIS implementation, the technical and regulatory aspect of data exchange needs to taken into account. A key factor related to the technical aspect is high-level interoperability to ensure that data transfers from source to target can be done regardless of the diversity in hardware and software platforms. An open architecture solution is therefore necessary to allow the smooth exchange of data and information from a different system that works in sync with systems inside and outside of university. Apart from technical issues, interoperability also needs to be regulated through the appropriate policies. This is essential in order to ensure uniformity in format and data exchange mechanisms among HEI for the purpose of guaranteeing high-level interoperability. 
International Journal of Software Engineering \& Applications (IJSEA), Vol.4, No.3, May 2013

\section{Architecture Used: Creating the foundation for WiS DEVELOPMENT}

Based on the previous analysis, this section shall explain on the information technology architecture model which serves as a reference model for WIS planning, design and organizing within HEI. The proposed EA-MDA model exhibits all activities required to develop the architecture for HEI, beginning from vision construction to implementation and evaluation. The WIS development process will specifically be described in detail by adopting the MDA-SOA approach. Figure 1 presents the proposed model.

Formulating the information technology architecture model for HEI is inextricably linked to the analysis of the university internal and external business functions as regulated by the government and set out in regulations on higher education in Indonesia. Business function is divided into two groups: primary business function and supporting business function. The primary business function of universities in Indonesia generally comprise primary business activities grounded in the Triple Principles of Higher Education Institutions, namely education, research and community service. The supporting business function on the other hand contains supporting business activities that include academic administrative management, human resource management, finance management and asset management. All of these activities must meet the QA and Executive Information standards.

\subsection{Enterprise Architecture}

\subsubsection{Business Architecture}

Business architecture in general describes the series of business activities, data and information found in the internal and external environments of the HEI. This phase is specifically meant to gain insight on the current situation of the business process before improvements are recommended by initiating the business architecture modeling process. HEI business architecture modeling may refer to HEI business functions already analyzed previously specifically by considering the primary and supporting business functions of the higher education institution. Business functions can be identified by using Porter's value chain approach. At this stage, modeling tools and basic methods such as Business Process Modelling Notation (BPMN) [23] and Unified Modeling Language (UML) [24] can be employed to develop the desired model. 


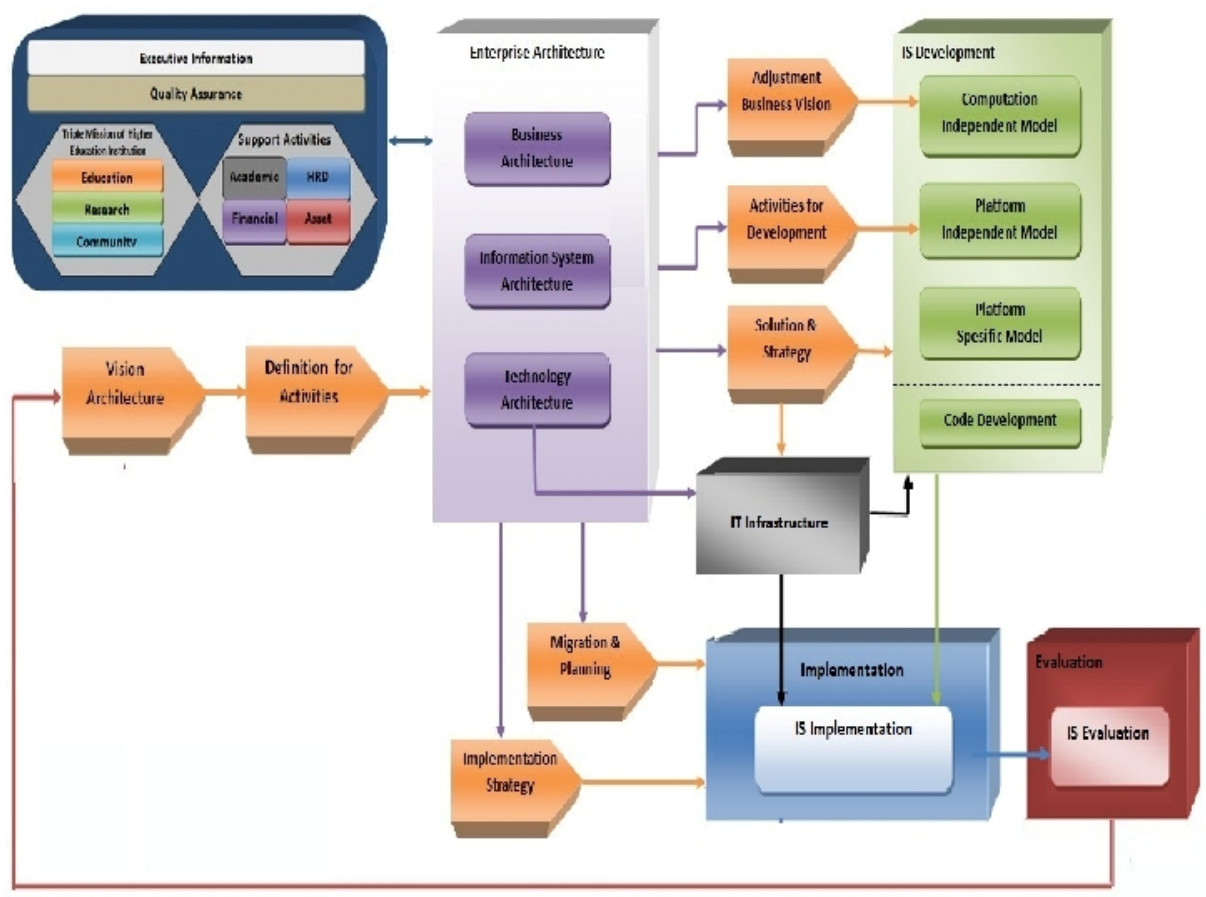

Figure 1. Information Technology Architecture Model

\subsubsection{Information System Architecture}

\section{a. Data Architecture}

Data architecture refers to the identification of data that supports business functions as defined in the business model explained earlier. Management requires centralized and integrated data sources in order to heighten coordination and synchronization of data management operations. Within the context of data architecture, university needs to avoid the repeated inputting of the same data. Data should be inputted only once and can subsequently be used simultaneously by relevant business processes. The data architecture currently developed by university still has weaknesses that need to be addressed before it can be integrated with data originating from other universities due to lack of integration in their data structures.

In this stage, data architecture is developed through the identification of the business function and organizational entity. Results of the identification process are then presented through an UML class diagram or a data functional matrix to illustrate the connection between business process and data entity through created, use, read and delete (CURD) functions. The relation between each data entity with another entity is analyzed then compared with the list of data currently being managed by the system. This comparison is necessary to ascertain on whether data covered in the data architecture entity is based on data description.

\section{b. Application Architecture}

Application architecture focuses more on the planning of application needs and creating of application models. Application architecture required by the HEI is an integrated, online application that runs on a standard platform. In addition, management also requires a dynamic application and real-time system to ensure the presentation of timely and accurate information. 
Application architecture can be described through the application interaction matrix of business functions within the organization or the technical reference model (TRM). Application is linked to business and organizational functions in order to keep track of the collective use of an application. The impact of application architecture towards existing applications is analyzed. The appropriate solutions are required in order to determine on whether available applications are to be maintained or modified, integrated into other applications or new applications developed.

\subsubsection{Technology Architecture}

Technology architecture seeks to identify technology platforms, analyze the use of current technology platform toward applications, and propose technology platforms related to university needs. The appropriate technology platform is selected by assessing current IT trends and developments such as trends in hardware, software, network, database, security and social network. Results of technology classification include the selection of viable technologies for technology platforms that shall support applications and the recommended technology development. The technology architecture model essentially describes how technology supports applications and user interaction when using the applications.

\subsection{Support Activities}

\subsubsection{Vision Architecture}

This stage involves the identification of management requirements, project scope and constraints, and the definition of advanced architecture and expected targets. These identified aspects are represented through the stated vision and mission, business goals, and business objectives. The output at this stage is the creation of the vision architecture to be used. To have an idea of the general universities vision in Indonesia, several samples of Indonesia's leading universities have been examined. From this sampling it can be conferred that the stated vision of university in general is to establish themselves as leading seats of learning of national and international repute by building on their respective core competencies. Their mission statement on the other hand aspires to deliver first-rate educational processes based on the Triple Principles of Higher Education Institutions.

\subsubsection{Definition for Activities}

Prior to starting work on the subsequent architecture model, it is necessary to document and define all data needs, data organizing applications and data sharing requirements in running the business process, and existing technology platforms employed within the enterprise. Documentation shall become the basis for architecture modeling and the following implementation plan. Based on the primary and supporting activities of the higher education institution, this stage shall define activities necessary for documentation purposes that cover literatures, surveys and interviews with relevant parties.

\subsubsection{Adjustment Business Vision}

Architectural models obtained in the previous stages will be reviewed at the next activity. The modeled business and application architecture in the previous stages is then re-assessed with regard to its compatibility with university business vision. This stage maps out the relation between application architecture and the achievement of the vision formulated earlier. The output of this activity will be the basis for the development of the system, especially at the CIM level in the MDA approach. 
International Journal of Software Engineering \& Applications (IJSEA), Vol.4, No.3, May 2013

\subsubsection{Activities for Development}

WIS development is also conducted based on the guidelines from the list of WIS development activities. This list is necessary to provide a more focused WIS development process, beginning from preparations for needs assessment to the eventual development of a systems design for use by the higher education institution. The output of this activity will be the basis for the development of the system, especially at the PIM level in the MDA approach.

\subsubsection{Solution and Strategy Development}

This activity is intended to identify main issues and seek viable solutions. From the results of the analysis on the current situation of the higher education institution and the architecture model produced, a gap analysis is conducted. Results of this gap analysis can become the solution and strategy for resolving issues. This stage is also performed to determine the priority of application development. These solutions and strategies in turn can serve as input for the subsequent process of developing a more comprehensive WIS and technology infrastructure need.

\subsubsection{Migration and Planning}

The migration strategy for a new WIS is required prior to the implementation. In this stage, a gap analysis is essential on the resource base, including changes that may arise upon the implementation of the system. In addition, it is also equally important to conduct an impact analysis of the new application architecture and the decision-making process towards new IT investments in order to ensure a complete planning process with regard to systems migration and implementation.

\subsubsection{Implementation Strategy}

This stage involves estimations on human resource, implementation schedule, costs and benefits of the plan and time required. This includes the formulation of recommendations for each development implementation, determining the implementing organization and guaranteeing the compatibility of systems development with the desired architecture. Risk management is another essential component that needs to be incorporated into the implementation plan in order to minimize potential risks, such as risks related to human resource, unmet implementation schedule and others.

\subsection{Technology Infrastructure}

The gap that might occur between the current architecture and propose architecture can be eliminated by means of fulfilling the needs of technology and information system. This stage is conducted through procurement for technology support needed to encounter the needs of the technology of addition or optimization technology.

\subsection{MDA-SOA based WIS Development}

The web information system development process is based on the MDA-SOA concept. Metamodeling defines the structure of models, and in an abstract way specifies the construct of a modeling language and their relations. Through this approach, it is necessary to determine a metamodel that suitably represents the web application. During the design phase, modeling is used to define requirements and provide model details at various levels. Next, model transformation is carried out in accordance with transformation rules. The models provide support for testing prior to implementation and also contribute to automatic code generation. 


\subsubsection{Computation Independent Model Level}

This stage is associated with an enterprise architecture particularly business architecture that already proposed in the previous stage. Business models need to describe the environment in which the system will be used, with no direct orientation on how it will be implemented. It also specify the requirements, use cases and the system's main flow from the customer's perspective.

\subsubsection{Platform Independent Model Level}

Modeling the systems process and structure can be done through these models in an independent way of the technological details for their implementation. The processes are captured by UML activity diagram and structures are capture by UML class diagram. These models can be modified or transformed into PSM that express the specific implementation process. For this particular study, the Model View Controller (MVC) pattern is applied as a target technology for the generated web application. Templates need to be defined in order to automatically generate the web application and conduct model transformations. They state transformation rules for changing a given model-to-model or model-to-text transformation. These templates are designed to implement the classes for Data Definition Language (DDL) scripts, Web Service Description Language (WSDL) and for the MVC_Controller of the MVC pattern that functions to receive requests, invoke the MVC_Model to perform the requested operations and send data to the MVC_View. MVC_View formats are to be presented in a web application as PHP files output. The defined templates also facilitate the generation of highly specific PSM from PIM.

\subsubsection{Platform Spesific Model Level}

Based on the models and templates identified earlier, the code generation process can proceed to automatically produce the source code. In this case, Acceleo [25] will be applied for creating the templates and producing a PHP-based web application [26]. Web application is implemented through the PHP scripting language and additional technologies, such as the Apache web server and MySQL database server, as the target environment for deployment, while the adoption of the CodeIgniter [27] PHP framework is based on the MVC pattern. All files generated are placed into the framework. The remaining part are created manually to finalize the entire process. The detail of WIS development steps as shown in Figure 2.

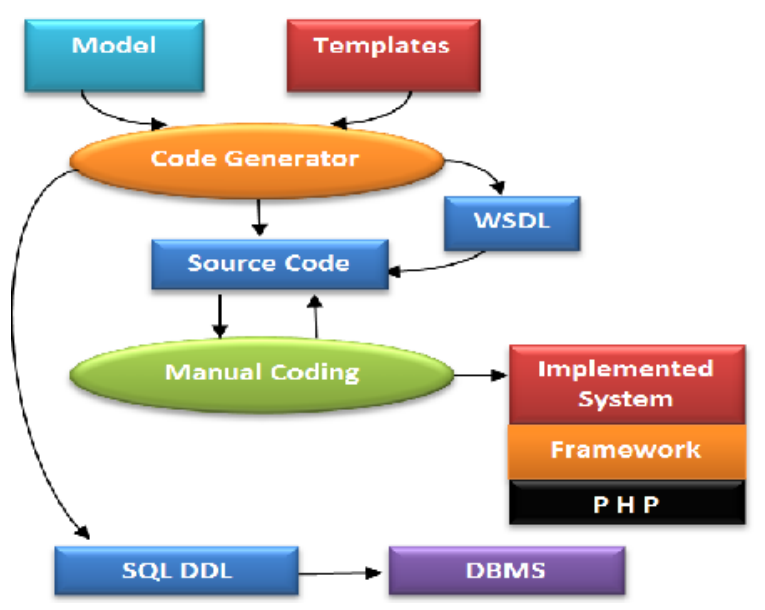

Figure 2. Detail of WIS development process 


\subsection{Implementation}

The implementation stage is where the WIS already developed in the previous phase is implemented. Through systems implementation, the outcomes can be operated and utilized optimally according to needs. At this stage, it can be determined on whether the system that has been developed can operate according to plans, and whether it can be utilized by the end user and meet the expected objectives. An evaluation is also conducted during this stage on shortcomings during the system development process, including a deficient requirements analysis, not modeled and unpredictable factors. As such, the necessary improvements can then be made to rectify these inadequacies.

\subsection{Evaluation}

Evaluation is an important aspect necessary for gleaning information on the extent to which the objectives of an WIS has been successfully achieved. Through evaluation, feedback will also be generated, crucial for improving WIS quality in the future. The main constraint in conducting evaluation is in determining the evaluation criteria, evaluation parameter and methodology for establishing the evaluation framework. Recent developments in information technology, particularly with regard to the internet, have made it even more difficult to gauge the level of success and effectiveness of an WIS compared to earlier conditions. WIS has brought forth a different set of conditions and factors that need to be considered, such as direct user interaction unrestricted by time, distance and place.

From previous studies, several recommended models for IS evaluation include Technology Acceptance Model (TAM) and IS-Impact. TAM introduces two key variables - Perceived Ease of Use (PEU) and Perceived Usefulness (PU) - that have central relevance to predict user acceptance [28]. Through the IS-Impact model, IS impact can be measured in terms of Information Quality (IQ), System Quality (SQ), Individual Impact (II) and Organizational Impact (OI) [29]. This however does not provide a comprehensive evaluation of Web-based information system. In view of this, the evaluation model for IS implementation is modified from the aforementioned models by incorporating specific measurements. The selection of the two existing models and the necessary modifications are essential with regard to WIS for the higher education institution in which the characteristics are different from other enterprises.

The defined dimensions for measuring WIS by adding 4 dimensions : User Capabilities (UC), Organisation Capabilities (OC), Information Effectiveness (IE) and System Effectiveness (SE). Based on the characteristics of the HEI, the dimensions used still needs to be adapted for specific user. For example, the OI dimension is not provided to the user student due to not directly related to the organization impact. The elements for measuring the dimensions consist of 19 elements for students, teachers and related working units user, 10 elements for System Developer, 10 elements for Managements as shown in Table 1. 
Table 1. Elements for measuring the dimensions

\begin{tabular}{|l|l|}
\hline \multicolumn{1}{|c|}{ User } & \multicolumn{1}{c|}{ Element } \\
\hline $\begin{array}{l}\text { Students, } \\
\text { Teachers, Staff } \\
\text { related working } \\
\text { units }\end{array}$ & $\begin{array}{l}\text { Enjoyment, Number of site visits, Number of transactions executed, } \\
\text { Availability, Reliability, Accessibility, Response time, Ease of use, Ease } \\
\text { of learning, Navigation patterns, Functions, Training, Services, Empathy, } \\
\text { Responsiveness, Assurance, Security, Integration, System features }\end{array}$ \\
\hline $\begin{array}{l}\text { System } \\
\text { Developer }\end{array}$ & $\begin{array}{l}\text { Conciseness, Timelines, Consistency, Maintainability, Applicability, } \\
\text { Server and Network Speed, Traceability, Security, Currency, Interactivity }\end{array}$ \\
\hline Management & $\begin{array}{l}\text { Cost reduction, Time savings, Improving work efficiency, Enhancement } \\
\text { of communication, Enhancement of coordination, Improved decision } \\
\text { making, Completeness, Relevance, Number of academic standards } \\
\text { procedure supported, Number of operational university supported }\end{array}$ \\
\hline
\end{tabular}

\section{WIS DEVELOPMENT : A CASE STUDY}

This section shall discuss on the application of the information technology architecture model recommended above to support WIS development at Unila as the case study. Unila is a stateowned university in Indonesia that runs 8 faculties, 54 undergraduate study programs (diploma and bachelor's degree), 12 post-graduate study programs (master's and $\mathrm{PhD}$ degree) and currently serves 28.116 students, 1120 lecturers and 707 administrative staff (data from academic year 2011).

Data and analysis on university activities related to its Business Function, Vision Architecture, and Definition for Activities required as input for modeling Unila's enterprise architecture are entirely based on current data and conditions necessary for Unila. Due to limited space, not all will be presented in this paper.

\subsection{Business Architecture}

For the modeling of the business process, Unila's business functions are identified and its organizational structure documented. These identified business functions are then linked to the working units in order to determine the responsibilities of working units in relation to a business function. Business functions are identified by using the value chain model that classifies business areas into primary activities and supporting activities of the enterprise. From this model, it can be concluded that Unila has five supporting activities and three primary activities.

Three primary activities related to education, research and community service while five supporting activities related to human resource, finance, asset, services and public relation management.

\subsection{Information System Architecture}

\subsubsection{Data Architecture}

Data architecture consists of both existing and planned data architecture. Data architecture draws from the business architecture explained earlier which refers to data required for facilitating three primary activities and five supporting activities. 


\subsubsection{Application Architecture}

Application architecture refers to current applications (as-is) and planned applications (to-be). An analysis is therefore necessary on ongoing applications to look at the business process and needs of working units. Analysis results on existing applications based on faculties, departments and working units responsible for managing the applications. In the development of current applications, Unila have three developments options, e.g., open-source based development, ownsource based development, and for some special purpose the application already be developed by the government and ready to be implemented. Available application technologies mostly use PHP and database and Oracle. A few other technologies still operate through Novel Netware by using DBF database. Websites use PHP and MySQL.

Analysis results on existing applications inform decisions on strategies to be implemented for WIS integration with the institution. Subsequently, to identify future application needs, a Strengths, Weaknesses, Opportunities, and Threats (SWOT) and Critical Success Factors (CSF) analyses are conducted to determine the future WIS solution model appropriate for the business process carried out by Unila. Figure 3 shows the analysis results of planned application (to-be) required by Unila. There are classified in the Academic management, Knowledge management, Resource management, IT Services, and Community Relationship Management (CRM) to support Quality Assurance and Executive information.

\subsection{Technology Architecture}

This particular phase is intended to identify the current technology platforms and how they are applied with regard to applications, and determine the recommended technology platforms that Unila requires. Unila's existing technology platforms identified include its data center equipped with 32 servers, 2000 desktop computers connected to the Local Area Network (LAN), and data storage in the form of SAN (Storage Area Network). Its intranet infrastructure that links internodal working units relies on a switching system applicable up to the faculty level whereby all switching functions are done through the manageable switch mode. Fiber optic as the main media backbone has $1 \mathrm{Gbps}$ in channel bandwidth. Wireless media is also used as the network infrastructure, although several study programs (30\% from all study programs in Unila) are still using cables and have yet to employ wireless technology. The existing technology platforms are largely support of the proposed application but still need optimization to improve the performance. From Unila's needs assessment, the technology required by the institution is a network technology that connects applications and allows easy access for end users. Technology platforms recommended for development must be those that adopt recent technological trends such as the latest in hardware, in memory computing (IMC), network, cloud computing, web 2.0., e-Learning 2.0, mobile computing, Internet of Things (IOT) and social network. 


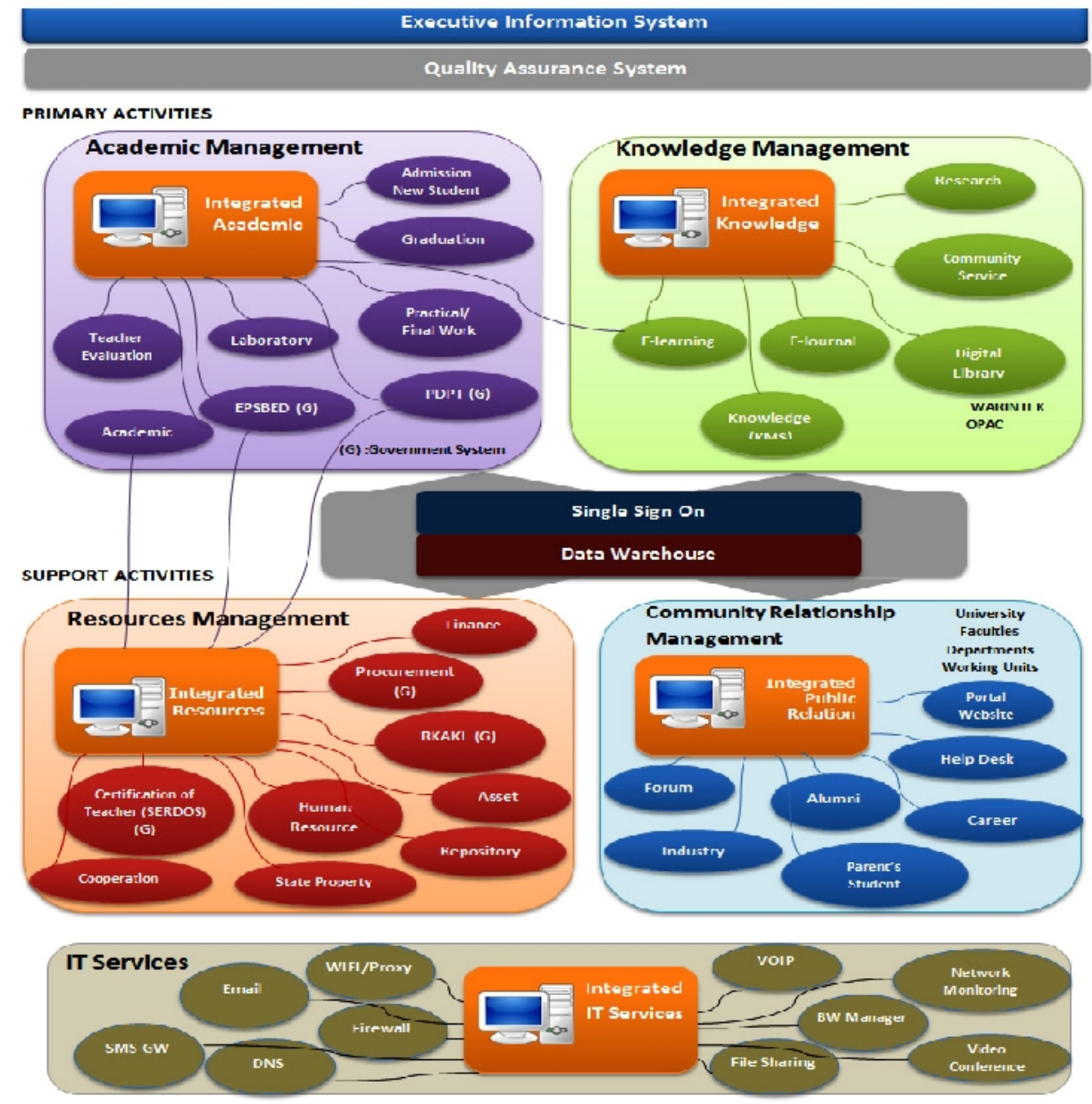

Figure 3. Application Architecture (to-be)

\subsection{Solution Strategy for Bridging the Gap}

Subsequent activities as follow up to architecture modeling include Adjustment Business Vision, Activities for Development, and Solution and Strategy Development. Based on the current situation of existing IS in Unila and HEI in general, solutions and strategies are formulated for integration purposes with regard to the presentation (user interface), applications, services and data. The integration is also perform with the data on DGHE (government application). Figure 4 presents the integration model architecture.

This particular phase also determines the list of priority for application development. The solution model produced can connect existing applications with other ongoing applications as well as with new applications without affecting the performance of the respective application. Concerning WIS development, based on Unila's needs assessment, the Academic management domain shall be given the highest development priority. The following example focuses on the development of a web information system (called SIMPEL) [30] to integrate the existing systems provided in the analysis results mentioned in section 6.2.2. 


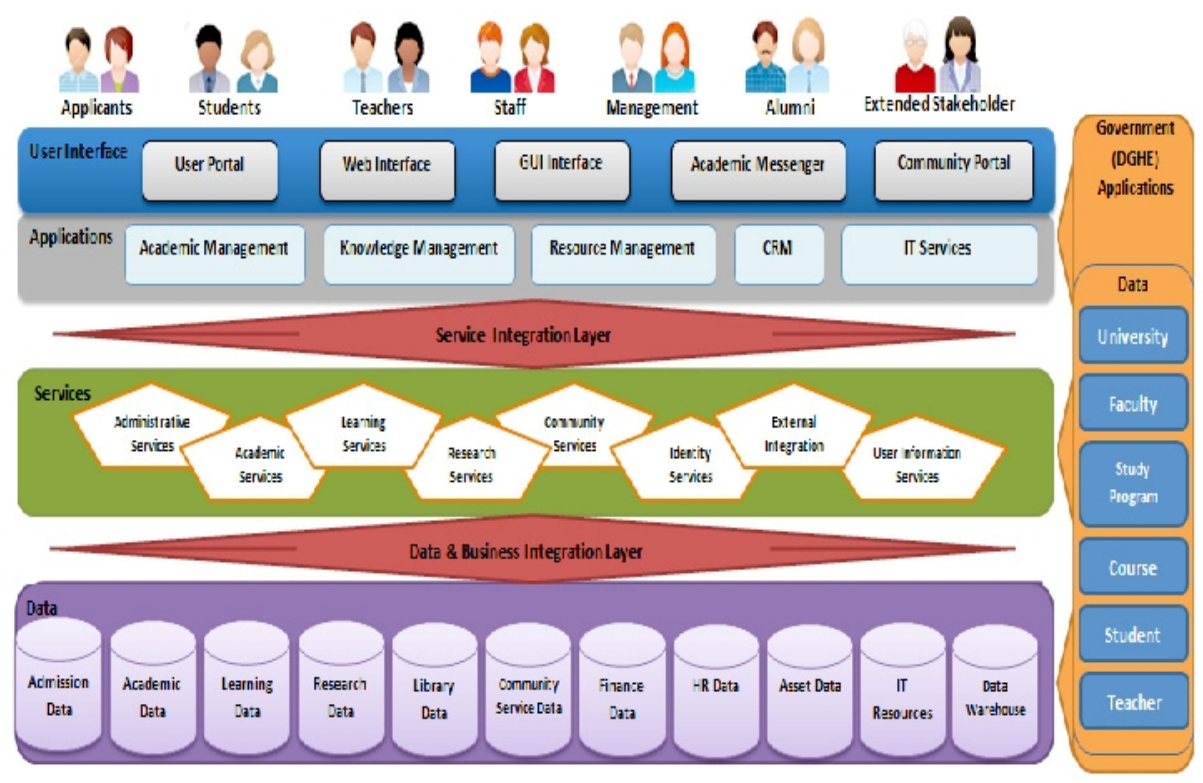

Figure 4. Integration Model Architecture

\subsection{Applying MDA-SOA based WIS Development}

In this work, a set of models is designed related to the WIS. A specific metamodel acquaintance of UML metamodel is created for this modeling process. Based on the result obtained from the modeling process, this process expects to generate artifacts that may help create the necessary web pages. Nevertheless, the modeling process only constitutes half of the entire MDA system. Templates to produce the target system are equally important. The usefulness of the templates is to transform a given model to text as shown in Table 2.

Table 2. The templates

\begin{tabular}{|l|l|c|}
\hline $\begin{array}{c}\text { Template } \\
\text { Name }\end{array}$ & \multicolumn{1}{|c|}{ Description } & $\begin{array}{c}\text { Total } \\
\text { Template }\end{array}$ \\
\hline MVC pattern & $\begin{array}{l}\text { A template for generating Model, View (user interface) } \\
\text { and Controller }\end{array}$ & 10 \\
\hline DDL & A template for generating DDL scripts to create the tables & 1 \\
\hline WSDL & A template for generating WSDL files & 1 \\
\hline
\end{tabular}

By using the defined templates and models, the generator code creates all application source code based on MVC pattern, DDL and WSDL files. The SIMPEL development in this work realized 107 FPs (Function Point). Handwritten (manual) codes need to be added after generation for complex business logic and graphical user interface (GUI) parts. Then the result of generated and handwritten code are tailored to the framework for system implementation. The development of WIS is combined with a framework CodeIgniter, leading to faster PHP web application development.

\subsection{WIS Implementation}

From the results obtained in the previous stages, the proposed WIS has not been entirely developed and implemented. Similarly, the proposed technology platform. This case study is taken to integrate two existing WIS by using a WIS that serves as an interface. The development process involved in implementing the approach allows developers to progress smoothly from 
requirements specification to the generation of the web application. The implementation of a WIS has successfully integrated Course Management System (CMS) MOODLE [31] into Unila's academic information system and work properly. The implemented SIMPEL is analyzed in the teaching/learning activities at Department of Electrical Engineering Unila on trial period in odd and even semester of the 2011/2012 academic year. During this period a total of 887 students were enrolled in 25 courses through the SIMPEL and follow the learning activities in MOODLE.

\subsection{WIS Evaluation}

The model adopted for WIS evaluation is a modification of the IS-Impact and TAM models with 12 dimensions of measurements. This model is applied to assess the quality and impact of SIMPEL implementation in Unila. The designed questionnaire is consists of 19 elements for user students and teachers. Given the time constraint in evaluating the implementation of SIMPEL, the evaluation process only involves participants representing user students and teachers and has yet to involve all stakeholders in Unila. Some 142 users have expressed their views through the questionnaire on SIMPEL implementation for the recommended dimensions. Results as shown in Table 3 reveal that $69.2 \%$ of users are satisfied with the SIMPEL (highly agree and agree), neutral $24.6 \%$ and $6.2 \%$ unsatisfied (disagree and highly disagree).

Table 3. Evaluation result

\begin{tabular}{|l|r|r|r|r|r|}
\hline \multicolumn{1}{|c|}{ Element } & $\begin{array}{c}\text { Highly } \\
\text { agree }\end{array}$ & Agree & Neutral & Disagree & $\begin{array}{c}\text { Highly } \\
\text { disagree }\end{array}$ \\
\hline Enjoyment & $64.9 \%$ & $26.6 \%$ & $7.1 \%$ & $1.4 \%$ & $0.0 \%$ \\
\hline Number of site visits & $62.1 \%$ & $30.5 \%$ & $5.7 \%$ & $1.8 \%$ & $0.0 \%$ \\
\hline $\begin{array}{l}\text { Number of } \\
\text { transactions executed }\end{array}$ & $32.1 \%$ & $45.6 \%$ & $19.2 \%$ & $3.2 \%$ & $0.0 \%$ \\
\hline Availability & $20.3 \%$ & $50.4 \%$ & $25.6 \%$ & $3.4 \%$ & $0.4 \%$ \\
\hline Reliability & $7.8 \%$ & $48.4 \%$ & $27.4 \%$ & $3.5 \%$ & $12.9 \%$ \\
\hline Accessibility & $5.7 \%$ & $43.8 \%$ & $32.7 \%$ & $5.3 \%$ & $12.5 \%$ \\
\hline Response time & $6.4 \%$ & $33.4 \%$ & $54.5 \%$ & $5.7 \%$ & $0.0 \%$ \\
\hline Ease of use & $7.4 \%$ & $62.7 \%$ & $26.0 \%$ & $3.9 \%$ & $0.0 \%$ \\
\hline Ease of learning & $20.7 \%$ & $52.0 \%$ & $25.3 \%$ & $2.1 \%$ & $0.0 \%$ \\
\hline Navigation patterns & $7.1 \%$ & $64.8 \%$ & $25.3 \%$ & $2.8 \%$ & $0.0 \%$ \\
\hline Functions & $20.0 \%$ & $53.8 \%$ & $19.1 \%$ & $6.9 \%$ & $0.1 \%$ \\
\hline Training & $18.2 \%$ & $49.8 \%$ & $15.1 \%$ & $4.4 \%$ & $12.5 \%$ \\
\hline Services & $17.5 \%$ & $30.4 \%$ & $36.1 \%$ & $3.5 \%$ & $12.5 \%$ \\
\hline Empathy & $7.1 \%$ & $60.2 \%$ & $29.5 \%$ & $3.2 \%$ & $0.0 \%$ \\
\hline Responsiveness & $18.5 \%$ & $31.3 \%$ & $45.2 \%$ & $4.6 \%$ & $0.4 \%$ \\
\hline Assurance & $30.1 \%$ & $40.6 \%$ & $21.9 \%$ & $7.3 \%$ & $0.2 \%$ \\
\hline Security & $22.1 \%$ & $57.8 \%$ & $19.0 \%$ & $1.1 \%$ & $0.0 \%$ \\
\hline Integration & $26.2 \%$ & $59.8 \%$ & $13.1 \%$ & $0.9 \%$ & $0.0 \%$ \\
\hline System features & $7.9 \%$ & $71.8 \%$ & $19.8 \%$ & $0.5 \%$ & $0.0 \%$ \\
\hline
\end{tabular}

Questionnaire results also show that the significant elements in SIMPEL are Number of site visits, Enjoyment and Integration. It show that SIMPEL effectively assist the teaching learning process. While the elements that must be improved are Accessibility, Training and Reliability. It shows that SIMPEL still need to be complemented and enhanced the quality. 
International Journal of Software Engineering \& Applications (IJSEA), Vol.4, No.3, May 2013

\section{Conclusions}

Based on an analysis of IT/IS of HEI in Indonesia, an EA-MDA-based information technology architecture model has been developed according to the situation and needs of national universities. This model is then applied to University of Lampung as a case study. The outcome is an architecture information technology that can be implemented to support integrated WIS development in Unila. One of the WIS developed in Unila has been implemented and subsequently evaluated which resulted in an impressive level of user satisfaction. This study is expected to specifically contribute to the advancement of HEI in Indonesia, particularly as reference for designing and building a comprehensive WIS. The definition of a complex architecture model shall help meet all university needs. Nevertheless, HEI need not force themselves to create unnecessary business processes, but it would be best for them to focus on areas most suited with their respective needs. The adoption of the MDA therefore substantially supports this concept. The future work we will find other strategies in addressing issues of the integrated WIS and focus on improve the models in each activities prior to developed.

\section{ACKNOWLEDGEMENTS}

The first author would like to thank the Directorate General of Higher Education (DGHE) of the Ministry of National Education of Indonesia that has provided the funding of this study. Thanks are also to the colleagues of the Department of Electrical engineering and Computer Centre University of Lampung for their help and support.

\section{REFERENCES}

[1] Osvalds, Gundars, (2001) Definition of Enterprise Architecture - Centric Models for The Systems Engineers, TASC Inc.

[2] T. Erl, (2005) Service-Oriented Architecture - Concepts, Technology, and Design, Prentice Hall.

[3] OMG, "OMG Model Driven Architecture," Available: http://www.omg.org/mda.

[4] Republic of Indonesia, (2005) "Government regulations (PP) No.19 of 2005 of national standard of education" ,Jakarta, Indonesia.

[5] Shah, H. \& Kourdi, M.E (2007) "Frameworks for Enterprise Architecture," IT Professional, vol.9, no.5, pp. 36-41

[6] Ostadzadeh, S. S, Aliee, Fereidoon S., Ostadzadeh, S. A., (2008), "An MDA-Based Generic Framework to Address Various Aspects of Enterprise Architecture", Advances in Computer and Information Sciences and Engineering, pp. 455-460.

[7] Wegmann, A. and Preiss, O., (2003) "MDA in Enterprise Architecture? The Living System Theory to the Rescue", Proceedings of the 7th IEEE international Enterprise Distributed Object Computing Conference (EDOC'03), pp. 2-13

[8] Fatolahi, Ali, S. S, Stéphane, C. L, Timothy (2007) “Enterprise Architecture Using the Zachman Framework: A Model Driven Approach”, Proceedings of the IRMA 2007 International Conference, pp 65-69.

[9] Cáceres, P., Marcos,E.,Vela ,B., (2003), “A MDA-Based Approach for Web Information System Development”, Workshop in Software Model Engineering (WISME'03)

[10] Castro,V., Marcos, E., Cáceres, P., (2004) "A User Service Oriented Method to Model Web Information Systems”, WISE 2004, LNCS 3306, pp. 41-52

[11] Meliá, S., \& Gómez,J.,(2005)" Applying Transformations to Model Driven Development of Web Applications “,ER Workshops 2005, LNCS 3770, pp. 63-73

[12] Castro, V. De., Marcos, E., and Vara, J.M., (2010), "Applying CIM-to-PIM model transformation for the service-oriented development of information systems," Journal Information and Software Technology, pp. 87-105 
International Journal of Software Engineering \& Applications (IJSEA), Vol.4, No.3, May 2013

[13] Carstensen, P. H., Vogelsang, L, (2001), "Design of Web-based information systems-new challenges for systems development?" Ninth European conference on information systems (ECIS), pp 536-547

[14] National Accreditation Board for Higher Education (Badan Akreditasi Nasional Perguruan Tinggi, BAN-PT) Ministry of Education Indonesia, (2008) Book IIIA: Undergraduate program study accreditation, Jakarta, Indonesia, BAN PT.

[15] Directorate General of Higher Education (DGHE), "Dissemination of national higher education database system", Ministry of Education Indonesia, (2010), Jakarta, Indonesia.

[16] Sowa, J. F., Zachman, J.A. (1992) "Extending and formalizing the framework for information systems architecture". IBM Systems Journal 31, No. 3, 590-616.

[17] The Open Group, TOGAF Version 9.1, http://www.opengroup.org/togaf/

[18] Leist,S., \& Zellner,G.,(2006), "Evaluation of current architecture frameworks". In Proceedings of the 2006 ACM symposium on Applied computing

[19] Frankel, David S.,(2003) The Model Driven Architecture: Applying MDA to Enterprise Computing, OMG Press.

[20] Open Group, (2009) The Open Group Architecture Framework: Architecture Development Method.

[21] Rivett,P., Spencer,J., Waskiewicz,F., (2005) TOGAF/MDA Mapping, White Paper, The Open Group

[22] Directorate General of Higher Education (DGHE), (2009), EPSBED, http://evaluasi.or.id/

[23] The OMG Group, (2008) Business Process Modelling Notation, Version 1.1.

[24] Booch, G., Rumbaugh, J., Jacobson, I., (1999) “The Unified Modeling Language: A User Guide”, Addison Wesley.

[25] Main Acceleo Site, “Acceleo MDA Generator,” http://www.acceleo.org/.

[26] Main PHP Site "PHP," http://www.php.net/.

[27] Main CodeIgniter Site , "CodeIgniter," http://codeigniter.com/.

[28] Chuttur, M.Y., (2009), "Overview of the Technology Acceptance Model: Origins, Developments and Future Directions”, Indiana University, USA, Sprouts: Working Papers on Information Systems

[29] Gable, G.,Sedera, D.,Chan, T. (2008), "Re-conceptualizing Information System Success: The ISImpact Measurement Model”, Journal of the Association for Information Systems, 9 (7), pp. 377-408.

[30] Mardiana \& Araki,K., (2012) "SIMPEL: An innovative web application interface supporting online course management system," in Information Technology Based Higher Education and Training (ITHET), pp.212-219.

[31] Main Moodle Site, "Moodle," http://moodle.org/

\section{Authors}

\section{Mardiana}

She received B.S. degree in Electrical Engineering at the National Institute of Technology, Indonesia and the M.S degree in Electrical Engineering at the Bandung Institute of Technology, Indonesia, in 1997 and 2002 respectively. Since 1998 until now, she is working as a lecturer at Department of Electrical Engineering, University of Lampung, Indonesia. She is currently a PhD student in Graduate School of Information Science and Electrical Engineering, Department of Advanced Information Technology, Kyushu University, Japan.

\section{Keijiro Araki}

He received his B.S., M.E. and D.E. degree in Computer Science and Communication Engineering from Kyushu University, Japan, in 1976, 1978 and 1982 respectively. Since 1984 till 1993 he was an Associate Professor in the same department. From 1993 to 1996 he was working as a Professor at the Graduate School of Information Science, Nara Institute of Science and Technology, Japan. Now, he is a Professor at the Graduate School of Information Science and Electrical Engineering in Kyushu University since 1996.
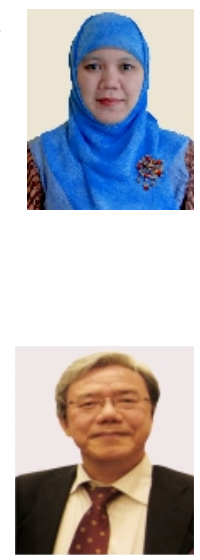